\title{
Common Type of Damages in Composites and Their Inspections
}

\author{
Amin Ghobadi \\ Engineering Faculty, Shahrekord University, Shahrekord, Iran \\ Email: aminghobadi@yahoo.com
}

How to cite this paper: Ghobadi, A (2017) Common Type of Damages in Composites and Their Inspections. World Journal of Mechanics, 7, 24-33.

http://doi.org/10.4236/wim.2017.72003

Received: January 29, 2017

Accepted: February 19, 2017

Published: February 22, 2017

Copyright $\odot 2017$ by author and Scientific Research Publishing Inc. This work is licensed under the Creative Commons Attribution International License (CC BY 4.0).

http://creativecommons.org/licenses/by/4.0/

\begin{abstract}
This paper is a short introduction to the common type of damages in composite structures and different ways of their inspection. Due to the high increase of interest in composite materials in past decades and their usage in different structures, there is a need to discuss the damage types in them along with different ways of inspection. This paper provides a short review of these facts in order to fill out the gap that there is in the literature. Major emphasis is placed on the damage types and their mechanisms and inspection methods, mostly focused on wave propagation based structural health monitoring (SHM).
\end{abstract}

\section{Keywords}

Composites, Damage, Inspection, Structural Health Monitoring (SHM), Non-Destructive Evaluation (NDE)

\section{Introduction}

Composite materials are increasingly used in many industries including aerospace, automotive, electrical industries, etc. Composites can be defined as two or more materials combined to form a single material. The increasing interest in composites is due to their significant advantages over metals, such as light weight, corrosion resistance, design flexibility, high strength, better fatigue life, etc. Composites also show an advantage over metal in low-temperature refrigeration systems [1] [2] and even in cryogenic environment. There are a few concerns which restrict the wider usage of composites: higher cost, complex fabrication, damage inspection, complex damage mechanism, etc. In general, composites can be categorized as fiber-reinforced and particle-reinforced [3]. Here the discussion is about fiber-reinforced composites.

As mentioned, composites have been used widely by different industries and more specifically in aerospace industries in past decades. Figure 1 has shown the 
increasing usage rate of composites in past four decades in aerospace industry [4], including the infrastructural installations which can affect the behavior of the electrical system by inducing harmonics as they role in insulations [5] or by affecting the internal electrical grid when used in the generators [6]. It is clear that the percentage of composites in aircraft designs is increased to more than $50 \%$. As an example, the extensive application of composites to the manufacturing and design of the A350-XWB, contributes to an almost $25 \%$ reduction in fuels consumption [7].

The greatest advantage of using composite materials is their ability to be tailored to design requirements. The structure can be made stiffer in one direction and more flexible in another. This implies that the structure can be designed to be exactly as strong and stiff as it needs to be, leading to improved structural weight, aero elasticity and ultimately fuel efficiency. Figure 2 illustrates the material distribution on the Boeing 787 [8].

In this paper, the common damage types in composites and different methods to inspect them are discussed shortly. In the next section, the damage mechanisms

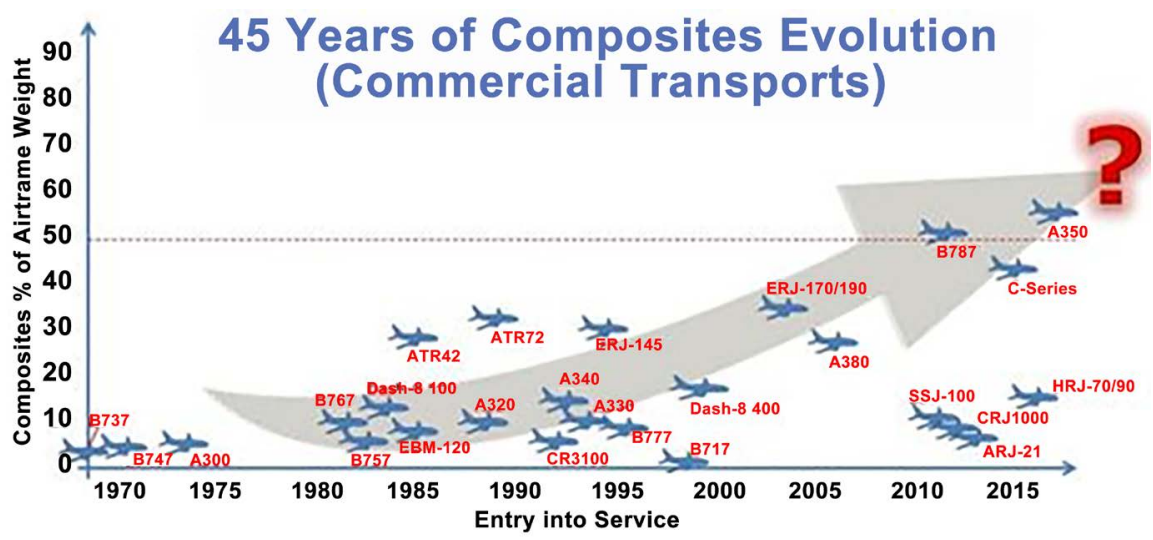

Figure 1. Increase in the use of composites over the last four decades [4].

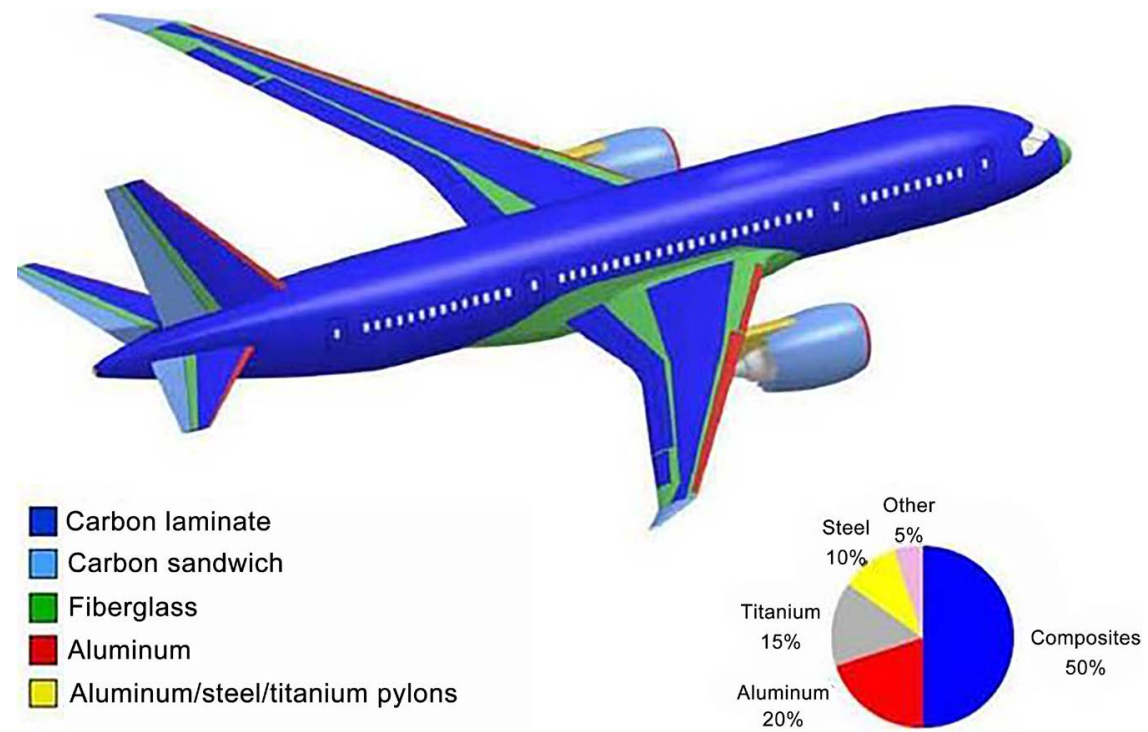

Figure 2. Material distribution on the Boeing 787 [8]. 
and different types of them in composites are discussed with supporting pictures. The last section provides the information about different methods for damage detection.

\section{Damage Types in Composites}

Damage mechanisms in composites are not as well understood as metals. Defects can be happen in composite materials and structures during the manufacturing process or in the service life of the structure/part/component.

The manufacturing process has a wide range of potential for causing defects in composites. The most common one is porosity which is the presence of a void in the matrix. The porosity can be caused by incorrect or non-optimal curing parameters (Figure 3) [9]. Inclusion of foreign bodies in matrix is another defect which happens during the manufacturing process which ranges from backing film to a greasy finger marks.

In service defects in composite structures, mostly happens due to impact damages. The most common defect due to the impact is delamination. In a laminated composite, delamination is separated layers, to form a mica-like structure with a significant loss in mechanical properties (Figure 4) [10]. Delamination in curved composite beams under different static loadings has been investigated extensively by Khoshravan et al. [11]. Matrix crack, fiber-matrix debonding, and fiber breakage also happen during the impact or other kind of severe loadings in composites. Figure 5 illustrates these phenomena in composite structures [12] [13] [14].

Other than impact, fatigue and lightning strikes can cause severe damages to composite structures and significantly reduce their mechanical properties. It is worth to mention that ply orientation of composite laminates has a significant role in stress concentration, fatigue life and mechanical properties of laminates [15] [16] [17] [18].

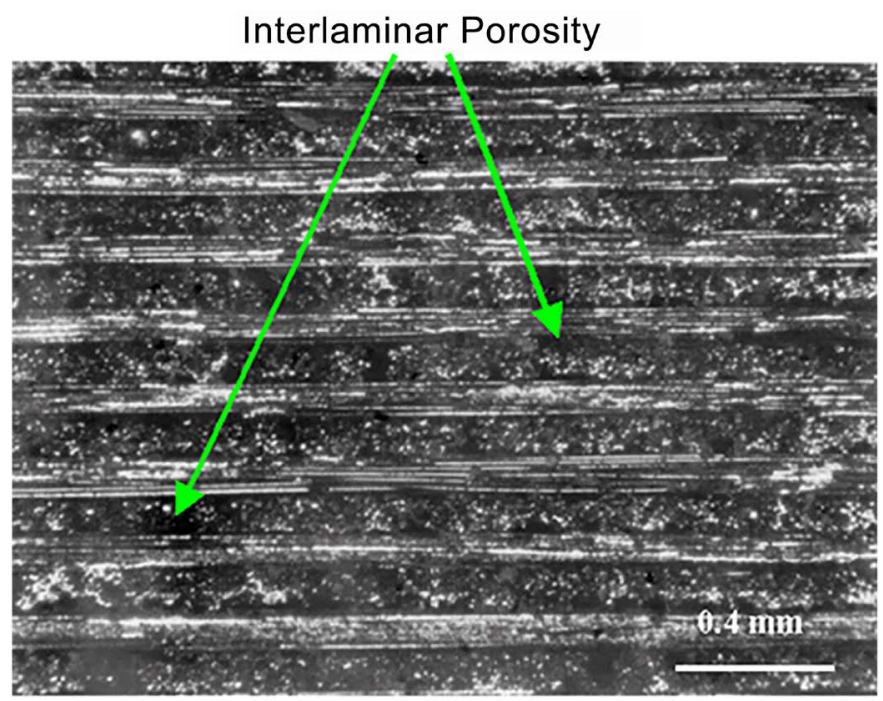

(b) Cross-sectional view

Figure 3. Porosity in a laminated composite [9]. 


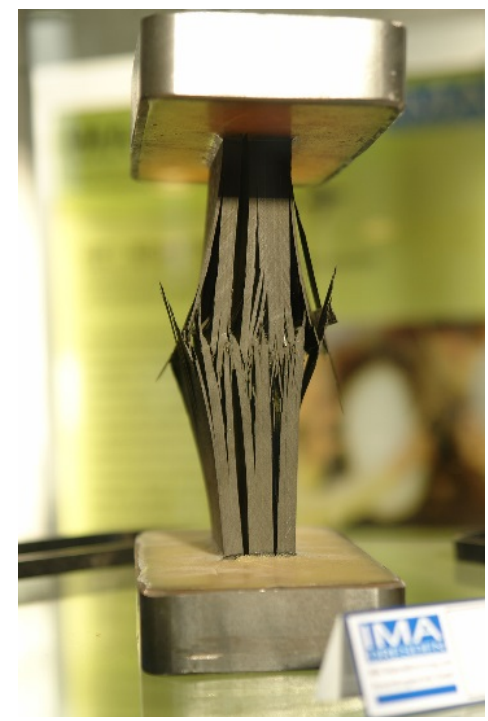

Figure 4. Delamination of CFRP under compression load [10].

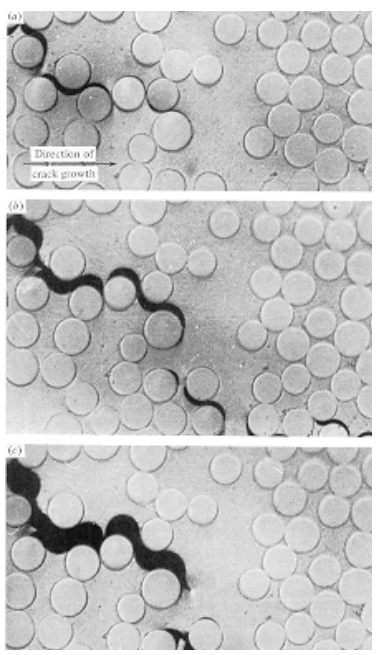

(a)

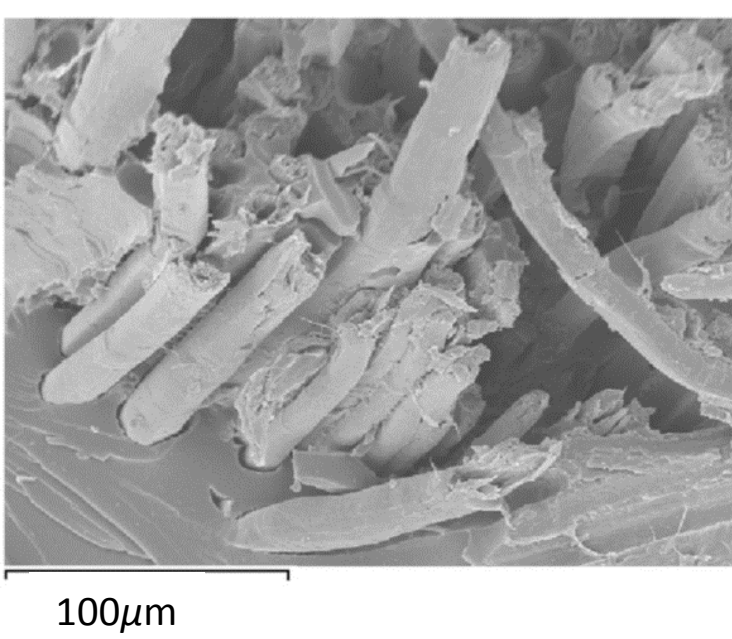

(b)

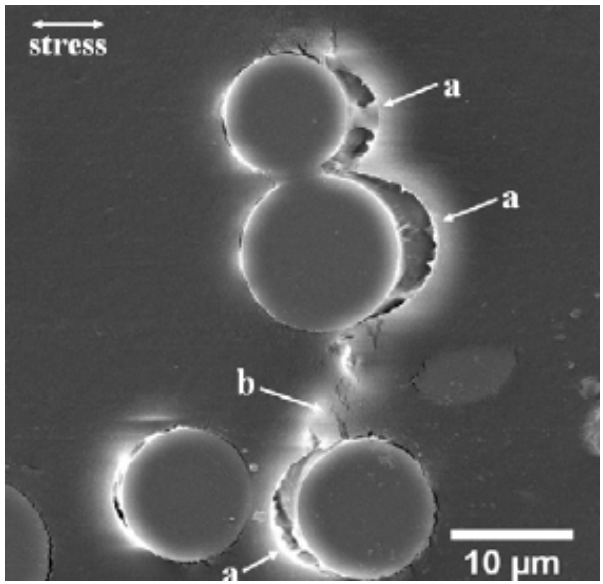

(c)

Figure 5. (a) Matrix crack; (b) Fiber breakage; and (c) Fiber-matrix debond while "a" shows the matrix-fiber debonding and "b" points to the matrix microcracks [12] [13] [14]. 
The growing usage of composite material in the structure of modern aircrafts has introduced new challenges. Aircrafts are vulnerable to the lightning strike that introduces direct and indirect effects in the skin of an aircraft. Damage development in a composite sample caused by flow of simulated lightning strike has been investigated by Gharghabi et al. [19] [20]. They have concluded that the flow of current impulse could induce irreversible damage and cause material property that might not be observable by simply inspecting the composite. This physical phenomenon has also, some practical implications that can be utilized in various high speed applications [21].

\section{Damage Detection in Composites}

In last couple of decades, lots of structural health monitoring (SHM) methods have been developed in order to detect the presence of the damage and predict its location [22] [23] [24] [25]. Guided wave base techniques are the most popular ones. The popularity comes from the sensitivity to small size damages, large detection area and low attenuation. Among the guided waves, Lamb waves are the most popular ones. Lamb waves are elastic waves between two surfaces. Reflection and scattering from defects in the structures is a well-known fact for Lamb waves and it can be used to localize damage in structure. Methods that are discussed here are all Lamb wave based SHM methods. Generally, a piezoelectric is used as an actuator to introduce Lamb wave to the structure.

Wave filed imaging is an SHM method which has been used widely by researchers [26] [27] [28] [29]. This method is the most suitable method for complex structures. In this method, the whole part is divided to small pixels and a sensor is attached to each pixel. The acquired signal at each pixel is used to reconstruct a picture of the structure. In order to acquire a high resolution picture of the structure, a high number of sensors must be attached to the structure which means that it increase the need of instrumentation and also it make it very time consuming.

Another method which has been introduced by Zhao et al. [30] is RAPID. RAPID is a reconstruction algorithm for the probabilistic inspection of defects. They tested a wing panel to find the damage location. Their results indicate that RAPID is capable of detecting the presence of the damage and find its location.

Cross-correlation method introduced by Veidt [31] is a method which uses the cross-correlation as the signal processing part. They used the envelopes of residual signal and excitation signal to perform the cross-correlation and calculate the damage index (DI) for each point on the plate. The highest DI shows the damage location.

Delay-and-sum method is based on the residual signal which is calculated by subtracting the baseline data from the current state data [32]. They used the Hilbert transform in order to find the wave travel time from actuator to the damage and scatter to sensors. Their method shows a high precision in localizing the damage.

Windowed Energy Arrival Method (WEAM) is first introduced by Sharif Kho- 
daei et al. [33]. Their work is based on the delay-and-sum method with few modifications. They applied a weight with a lognormal distribution on the results in order to avoid the boundary reflections and improve the damage detection results.

All of the listed SHM methods need a baseline data to be compared to real time data from sensors. Most reliable method to obtain the baseline data is experimental tests. Testing the structures in every single condition of their service life is an impossible job. Most researchers employ the FEM in order to obtain the baseline data [34] [35], but the FEM are computationally very expensive [36] [37] [38]. Furthermore, FEM equations are invalid in discontinuities like cracks tips. One alternative is to use meshless approaches such as peridynamics. Yaghoobi and Chorzepa [39] [40] introduced a framework based on peridynamics to model fiber reinforcement in cementitious composites. Furthermore, unguided and complex fracture behavior of fiber reinforced composite beams is investigated using micropolar peridynamics by Yaghoobi and Chorzepa [41]. Another alternative way is using spectral finite elements method (SFEM). SFEM was popularized first by Doyle [42] using Fourier based SFEM (FSFEM) and proved to be computationally very efficient compared to FEM. Later on other researchers introduced new methods such as wavelet spectral finite element (WSFE) [43]. The major drawback of SFEM is in the modeling of realistic structures and complex features.

Khalili et al. [44] [45] introduced WSFE-based UEL for 1-D composite beams in order to overcome the drawback of WSFE in modeling complex features. They improved their methods to simulate delamination in composite beams [46]. Later on, they developed WSFE-based UEL to simulate 2-D composite structures [47] [48]. Their works show that WSFE-based UEL has the computational efficiency of WSFE along with the ability of modeling realistic structures. These newly developed elements have a very high potential to be employed to make the baseline data for SHM purposes as it has been proved in their latest paper [49].

In addition to the previous methods, the frequency response functions coupled with machine learning techniques are of great importance in damage detection of composites and other complex structures [50]. In [51] [52] [53] [54], an Euler-Bernoulli model is developed to mimic the behavior of a damaged composite where various types of delamination are inspected by implanting an artificial immune based approach.

\section{Conclusion}

There is an increasing interest in composites in different industries due to their advantages to other engineering materials. However, because the damage mechanism in composites is not as well understood as metals; there is a resistance as well. In this paper, different damages and their inspection methods were discussed. Porosity, delamination, matrix crack, fiber breakage and fiber-matrix debond are among the most common damages in composites. These damages can be happen during the life time due to severe loading or because of manufacturing process. 
Due to the anisotropic nature of composites, detecting the possible damages has its own difficulties which have been discussed in the text.

\section{Acknowledgements}

The author would like to thank Dr. Hossein Golestanian for his significant help during this research.

\section{References}

[1] Aghniaey, S., Mohammad, S. and Mahmoudi, S. (2014) Exergy Analysis of a Novel Absorption Refrigeration Cycle With Expander and Compressor. Indian Journal of Scientific Research, 1, 815-822.

[2] Aghniaey, S., Seyed Mahmoudi, S.M. and Khalilzadeh-Sharghi, V. (2014) A Comparison between the Novel Absorption Refrigeration Cycle and the Conventional Ammonia-Water Absorption Refrigeration Cycle. International Conference on Heat Transfer, Fluid Mechanics and Thermodynamics, Orlando, 14-16 July 2014, 1986-1992.

[3] Agarwal, B.D., Broutman, L.J. and Chandrashekhara, K. (2006) Analysis and Performance of Fiber Composites. John Wiley, Hoboken.

[4] Red, C. (2014) Composite World. Http://www.compositesworld.com/blog/2014

[5] Norouzi, H., Abedi, S., Jamalzadeh, R., Rad, M.G. and Hosseinian, S.H. (2014) Modeling and Investigation of Harmonic Losses in Optimal Power Flow and Power System Locational Marginal Pricing. Energy, 68, 140-147. https://doi.org/10.1016/j.energy.2014.02.010

[6] Jouybari Moghaddam, H., Hosseinian, S.H., Vahidi, B. and Ghiasi Rad, M. (2012) Smart Control Mode Selection for Proper Operation of Synchronous Distributed Generators. 2nd Iranian Conference on Smart Grids, Tehran, 24-25 May 2012, 1-4.

[7] Airbus. http://www.1001crash.com/index-Page-Composite-Lg-2.html

[8] Freissinet, S. 1001 Crash. http://www.1001crash.com/index-Page-Composite-Lg-2.html

[9] Jeongguk, K., Liaw, P.K. and Wang, H. (2003) The NDE Analysis of Tension Behavior in Nicalon/SiC Ceramic Matrix Composites. Journal of the Minerals, 55, 1-13.

[10] Wikipedia. https://en.wikipedia.org/wiki/Delamination

[11] Khoshravan, M.R. and Khalili, A. (2015) Modeling of Failure by Delamination in Curved Composite Beams. Applied Mathematics in Engineering, Management and Technology, 3, 31-42.

[12] Hull, D. and Clyne, T.W. (1996) An Introduction to Composite Materials. Cambridge University Press, Cambridge. https://doi.org/10.1017/CBO9781139170130

[13] Muñoz, E. and García-Manrique, J.A. (2015) Water Absorption Behaviour and Its Effect on the Mechanical Properties of Flax Fibre Reinforced Bioepoxy Composites. International Journal of Polymer Science, 2015, 1-10.

[14] Arif, M.F., Meraghni, F., Chemisky, Y., Despringre, N. and Robert, G. (2014) In Situ Damage Mechanisms Investigation of PA66/GF30 Composite: Effect of Relative Humidity. Composites Part B: Engineering, 58, 487-495. https://doi.org/10.1016/j.compositesb.2013.11.001

[15] Khoshravan, M.R., Samaei, M. and Khalili, A. (2010) Numerical Analysis of the Situation of Holes for Decreasing the Stress Concentration in Composite Plates in Bolted Joints. 9th Annual Iranian Aerospace Society Conference, Tehran, 11-13 
May 2010.

[16] Khoshravan, M.R., Samaei, M. and Paykani, A. (2011) Numerical Investigation on the Position of Holes for Reducing Stress Concentration in Composite Plates with Bolted and Riveted Joints. Theoretical and Applied Mechanics Letters, 1, Article ID: 041005. https://doi.org/10.1063/2.1104105

[17] Masoomi, M. (2014) Numerical Modeling of Thermal Effects during Selective Laser Melting. 10th Mississippi State Conference on Differential Equations and Computational Simulations, Starkville, 23-25 October 2014.

[18] Masoomi, M., Gao, X., Thompson, S.M., Shamsaei, N., Bian, L. and Elwany, A. (2015) Modeling, Simulation and Experimental Validation of Heat Transfer during Selective Laser Melting. ASME 2015 International Mechanical Engineering Congress and Exposition, Houston, 13-19 November 2015, V02AT02A007. https://doi.org/10.1115/imece2015-52165

[19] Gharghabi, P., Lee, J., Mazzola, M.S. and Lacy, T.E. (2016) Development of an Experimental Setup to Analyze Carbon/Epoxy Composite Subjected to Current Impulses. Proceedings of American Society for Composites Annual Technical Conference, Williamsburg, 19-22 September 2016.

[20] Peyman, D.-B., Pedram, G. and Kaveh, N. (2011) Impact of Metal Thickness and Field Shaper on the Time-Varying Processes during Impulse Electromagnetic Forming in Tubular Geometries. Journal of the Korean Physical Society, 59, 3560. https://doi.org/10.3938/jkps.59.3560

[21] Peyman, D.B., Pedram, G. and Kaveh, N. (2011) Dynamic Analysis of a Fast-Acting Circuit Breaker (Thompson) Drive Mechanism. Journal of the Korean Physical Society, 59, 3547-3554. https://doi.org/10.3938/jkps.59.3547

[22] Boller, C., Chang, F.-K. and Fujino, Y. (2009) Encyclopedia of Structural Health Monitoring. Vol. 4, Wiley, Hoboken. https://doi.org/10.1002/9780470061626

[23] Diamanti, K. and Soutis, C. (2010) Structural Health Monitoring Techniques for Aircraft Composite Structures. Progress in Aerospace Sciences, 46, 342-352. https://doi.org/10.1016/j.paerosci.2010.05.001

[24] Raghavan, A. and Cesnik, C.E.S. (2007) Review of Guided-Wave Structural Health Monitoring. The Shock and Vibration Digest, 39, 91-114. https://doi.org/10.1177/0583102406075428

[25] Su, Z., Ye, L. and Lu, Y. (2006) Guided Lamb Waves for Identification of Damage in Composite Structures: A Review. Journal of Sound and Vibration, 295, 753-780. https://doi.org/10.1016/j.jsv.2006.01.020

[26] Rogge, M.D. and Leckey, C.A.C. (2013) Characterization of Impact Damage in Composite Laminates Using Guided Wavefield Imaging and Local Wavenumber Domain Analysis. Ultrasonics, 53, 1217-1226.

https://doi.org/10.1016/j.ultras.2012.12.015

[27] Sohn, H., Dutta, D., Yang, J.Y., Park, H.J., DeSimio, M., Olson, S., et al. (2011) Delamination Detection in Composites through Guided Wave Field Image Processing. Composites Science and Technology, 71, 1250-1256. https://doi.org/10.1016/j.compscitech.2011.04.011

[28] Kudela, P., Radzieński, M. and Ostachowicz, W. (2015) Identification of Cracks in Thin-Walled Structures by Means of Wavenumber Filtering. Mechanical Systems and Signal Processing, 50-51, 456-466. https://doi.org/10.1016/j.ymssp.2014.05.041

[29] Radzieński, M., Doliński, Ł., Krawczuk, M. and Palacz, M. (2013) Damage Localisation in a Stiffened Plate Structure Using a Propagating Wave. Mechanical Systems and Signal Processing, 39, 388-395. https://doi.org/10.1016/j.ymssp.2013.02.014

[30] Zhao, X., Qian, T., Mei, G., Kwan, C., Zane, R., Walsh, C., et al. (2007) Active 
Health Monitoring of an Aircraft Wing with an Embedded Piezoelectric Sensor/Actuator Network: II. Wireless Approaches. Smart Materials and Structures, 16, 1218-1225. https://doi.org/10.1088/0964-1726/16/4/033

[31] Veidt, M., Hames, S., Ng, C.T. and Wattinger, T. (2008) Imaging Laminar Damage in Plates Using Lamb Wave Beamforming. Advanced Materials Research, 47-50, 666-669. https://doi.org/10.4028/www.scientific.net/AMR.47-50.666

[32] Michaels, J.E. and Michaels, T.E. (2007) Guided Wave Signal Processing and Image Fusion for in Situ Damage Localization in Plates. Wave Motion, 44, 482-492. https://doi.org/10.1016/j.wavemoti.2007.02.008

[33] Sharif-Khodaei, Z. and Aliabadi, M.H. (2014) Assessment of Delay-and-Sum Algorithms for Damage Detection in Aluminium and Composite Plates. Smart Materials and Structures, 23, Article ID: 75007. https://doi.org/10.1088/0964-1726/23/7/075007

[34] Sarfi, V., Hemmati, V. and Arabshahi, M.M. (2014) Simulation of PTC Devices as Fault Current Limiters in Power Systems by Finite Element Method. International Conference on High Voltage Engineering and Application, Poznan, 8-11 September 2014, 1-4. https://doi.org/10.1109/ichve.2014.7035503

[35] Sarfi, V. and Hemmati, V. (2014) Simulation of Partial Discharge in Closely Coupled Cavities Embedded in Solid Dielectrics by Finite Element Method. International Conference on High Voltage Engineering and Application, Poznan, 8-11 September 2014, 1-4. https://doi.org/10.1109/ichve.2014.7035406

[36] Shiadeh, S.J., Ardebili, M. and Moamaei, P. (2015) Three-Dimensional Finite-Element-Model Investigation of Axial-Flux PM BLDC Machines with Similar Pole and Slot Combination for Electric Vehicles. 2015 IEEE Power and Energy Conference at Illinois, Champaign, 20-21 February 2015, 1-4. https://doi.org/10.1109/PECI.2015.7064936

[37] Jafarishiadeh, S., Ardebili, M. and Marashi, A.N. (2016) Investigation of Pole and Slot Numbers in Axial-Flux PM BLDC Motors with Single-Layer Windings for Electric Vehicles. 24th Iranian Conference on Electrical Engineering (ICEE), Shiraz, 10-12 May 2016, 1444-1448. https://doi.org/10.1109/iraniancee.2016.7585748

[38] Chakherlou, T.N. and Yaghoobi, A. (2010) Numerical Simulation of Residual Stress Relaxation around a Cold-Expanded Fastener Hole under Longitudinal Cyclic Loading Using Different Kinematic Hardening Models. Fatigue \& Fracture of Engineering Materials \& Structures, 33, 740-751. https://doi.org/10.1111/j.1460-2695.2010.01485.x

[39] Yaghoobi, A. and Chorzepa, M.G. (2015) Meshless Modeling Framework for Fiber Reinforced Concrete Structures. Computers \& Structures, 161, 43-54. https://doi.org/10.1016/j.compstruc.2015.08.015

[40] Yaghoobi, A. and Chorzepa, M.G. (2017) Fracture Analysis of Fiber Reinforced Concrete Structures in the Micropolar Peridynamic Analysis Framework. Engineering Fracture Mechanics, 169, 238-250. https://doi.org/10.1016/j.engfracmech.2016.11.004

[41] Chorzepa, M.G. and Yaghoobi, A. (2016) Innovative Meshless Computational Method for the Analysis of Fiber-Reinforced Concrete (FRC) Structures. Geotechnical and Structural Engineering Congress, Phoenix, 14-17 February 2016, 1209-1221. https://doi.org/10.1061/9780784479742.101

[42] Doyle, J.F. (1997) Wave Propagation in Structures. Springer, New York. https://doi.org/10.1007/978-1-4612-1832-6

[43] Gopalakrishnan, S. and Mitra, M. (2010) Wavelet Methods for Dynamical Problems. 
[44] Khalili, A., Samaratunga, D., Jha, R. and Gopalakrishnan, S. (2014) Wavelet Spectral Finite Element Modeling of Laminated Composite Beams with Complex Features. Proceedings of the American Society of Composites 2014-Twenty-Ninth Technical Conference on Composite Materials, San Diego, 8-10 September 2014.

[45] Khalili, A., Jha, R. and Samaratunga, D. (2017) The Wavelet Spectral Finite Element-Based User-Defined Element in Abaqus for Wave Propagation in One-Dimensional Composite Structures. Simulation: Transactions of the Society for Modeling and Simulation International, 1-12. https://doi.org/10.1177/0037549716687377

[46] Khalili, A., Samaratunga, D., Jha, R., Lacy, T.E. and Gopalakrishnan, S. (2015) Wavelet Spectral Finite Element Based User-Defined Element in ABAQUS for Modeling Delamination in Composite Beams. 23rd AIAA/AHS Adaptive Structures Conference, Kissimmee, 5-9 January 2015, 1-11.

https://doi.org/10.2514/6.2015-1726

[47] Khalili, A., Samaratunga, D., Jha, R., Lacy, T.E. and Gopalakrishnan, S. (2015) WSFE-Based User-Defined Elements in ABAQUS for Modeling 2D Laminated Composites with Complex Features. 30th ASC Technical Conference, East Lansing, 28-30 September 2015

[48] Khalili, A., Jha, R. and Samaratunga, D. (2016) Spectrally Formulated User-Defined Element in Conventional Finite Element Environment for Wave Motion Analysis in 2-D Composite Structures. European Journal of Computational Mechanics, 25, 446474.

[49] Khalili, A., Jha, R. and Jayakody, N. (2017) Structural Health Monitoring of SkinStiffener Structures Using WSFE-Based User Defined Elements in Abaqus. 25th AIAA/AHS Adaptive Structures Conference, Grapevine, 9-13 January 2017. https://doi.org/10.2514/6.2017-1677

[50] Abbasi, F., Mojtahedi, A. and Ettefagh, M.M. (2015) Fault Diagnosis Using Noise Modeling and a New Artificial Immune System Based Algorithm. Earthquake Engineering and Engineering Vibration, 14, 725-741. https://doi.org/10.1007/s11803-015-0057-7

[51] Mohebbi, B., Abbasidoust, F., Ettefagh, M.M. and Biglari, H. (2013) Delamination Diagnosis in Composite Beam Using AIS and BGA Algorithms Based on Vibration Characteristics. Springer International Publishing, New York, 73-89. https://doi.org/10.1007/978-3-319-00717-5_5

[52] Mohebbi, B., Abbasidoust, F. and Ettefagh, M.M. (2012) Delamination Detection in CFRP Composite Beam Using Modified AIS Algorithm. 2012 International Symposium on Innovations in Intelligent Systems and Applications, Trabzon, 2-4 July 2012, 1-5. https://doi.org/10.1109/inista.2012.6246987

[53] Babaei, M., Babaei, M. and Nourirad, G. (2014) Analysis of Influential Factors in Determining Very Fast Transient Overvoltages of GIS Substations. 2014 IEEE 8th International Power Engineering and Optimization Conference, Langkawi, 24-25 March 2014, 79-84. https://doi.org/10.1109/peoco.2014.6814403

[54] Babaei, M., Babaei, M. and Niasati, M. (2013) Parametric Analysis of Overvoltages Caused by Back-Flashover in "Siah-Bishe" 400 kV GIS Substation. 2013 3rd International Conference on Electric Power and Energy Conversion Systems, Istanbul, 24 October 2013, 1-6. https://doi.org/10.1109/EPECS.2013.6713049 
Submit or recommend next manuscript to SCIRP and we will provide best service for you:

Accepting pre-submission inquiries through Email, Facebook, LinkedIn, Twitter, etc. A wide selection of journals (inclusive of 9 subjects, more than 200 journals)

Providing 24-hour high-quality service

User-friendly online submission system

Fair and swift peer-review system

Efficient typesetting and proofreading procedure

Display of the result of downloads and visits, as well as the number of cited articles Maximum dissemination of your research work

Submit your manuscript at: http://papersubmission.scirp.org/

Or contact wjm@scirp.org 